\title{
Unravelling the genetics of spermatogenic failure
}

\author{
Liesbeth Visser and Sjoerd Repping \\ Department of Obstetrics and Gynecology, Centre for Reproductive Medicine, Academic Medical Centre, University \\ of Amsterdam, Meibergdreef 9, 1105 AZ Amsterdam, The Netherlands
}

Correspondence should be addressed to S Repping; Email: s.repping@amc.uva.nl

\begin{abstract}
Subfertility, defined as the inability to conceive within 1 year of unprotected intercourse, affects $10-15 \%$ of couples. In up to $55 \%$ of couples, the male partner is diagnosed with spermatogenic failure, i.e. one or more semen parameters fall below the WHO criteria for normozoospermia. In these cases, assisted reproductive technology is usually used to achieve pregnancy. Both genetic and environmental factors are thought to underlie spermatogenic failure. Despite years of research, only few genetic factors have clearly been shown to cause spermatogenic failure, and the identification of additional genetic causes or risk factors has proven to be extremely difficult. In this review, we will present an overview of established genetic causes of spermatogenic failure, describe pitfalls in searching for novel genetic factors and discuss research opportunities for the future.
\end{abstract}

Reproduction (2010) 139 303-307

\section{Male infertility: introduction to the problem}

Subfertility is of major clinical, social and economical concern. In the western world, one in eight couples does not conceive spontaneously within 1 year of unprotected intercourse (de Kretser 1997). In up to $55 \%$ of couples seeking medical attention, the male partner is diagnosed with spermatogenic failure, defined as one or more semen parameters falling below the WHO cut-off for normozoospermia (De Kretser \& Baker 1999). The prognostic value of this diagnosis is limited, as female parameters also contribute to the couple's (sub)fertility. As semen parameters therefore cannot fully discriminate between fertile and subfertile men, reduced semen parameters are generally interpreted as a reduced chance of spontaneous pregnancy (Bonde et al. 1998, Guzick et al. 2001, Aitken 2006).

Less than 20 years ago, couples of which the man had azoospermia or severe oligozoospermia were doomed to remain childless. It was the introduction of ICSI that allowed these men to obtain offspring (Palermo et al. 1992). Subsequently, this technique was used successfully in men with ejaculatory azoospermia by injecting spermatozoa that were surgically retrieved from the epididymis (through microsurgical sperm aspiration) or testis (by testicular sperm extraction). At the same time, the development of ICSI spurred research into the genetic causes of low semen quality, following questions on the health status of children conceived using ICSI and the risk of transmitting spermatogenic failure to male ICSI offspring (Silber \& Repping 2002). Follow-up data of ICSI children at 5 years of age indicate that, compared with naturally conceived children, children conceived through ICSI have an increased risk of congenital malformations, especially urogenital malformations in ICSI boys (Bonduelle et al. 2005).

Besides uncovering genetic causes of spermatogenic failure in light of diagnostic testing and counselling, the ultimate goal of studying spermatogenic failure is to develop a treatment for spermatogenic failure. Currently, the 'treatment' of spermatogenic failure consists of ovarian hyperstimulation of the unaffected female partner, which is both costly and burdensome and with potential unknown long-term side effects. Strikingly, as of today, there are no means to treat spermatogenic failure directly, except for treatment with a dopamine agonist in case of hyperprolactinaemia and treatment with gonadotrophins in case of hypogonadotrophic hypogonadism.

\section{Known causes of spermatogenic failure}

Spermatogenesis is governed by the parallel and serial actions of thousands of genes (Sha et al. 2002, Schultz et al. 2003, Schlecht et al. 2004, Ellis et al. 2007, Zamudio et al. 2008). In theory, alterations in any of these genes or their expression may cause spermatogenic failure. In reality, only a handful of genetic alterations have clearly been shown to cause spermatogenic failure (Nuti \& Krausz 2008).

First, numerical and structural chromosomal abnormalities interfere with normal meiosis and can therefore cause spermatogenic failure (Tuerlings et al. 1998). 
Klinefelter's syndrome $(47, X X Y)$ is the most commonly found numerical abnormality. Structural abnormalities that are often encountered include reciprocal translocations, Robertsonian translocations and pericentric inversions (Tuerlings et al. 1998, Dohle et al. 2002).

Second, five recurrent Y-chromosome deletions, the so-called AZFa, P5/proximal P1 (AZFb), P5/distal P1, $b 2 / b 4(A Z F C)$ and $g r / g r$ deletions, are associated with spermatogenic failure (Reijo et al. 1995, Vogt et al. 1996, Repping et al. 2002, 2003, Visser et al. 2009). These deletions all remove multiple genes that are potentially involved in normal human spermatogenesis. It is currently unknown which of these individual genes or any combination thereof play an essential role, and in which dosage (Noordam \& Repping 2006).

Third, a number of monogenic disorders, listed in the Online Mendelian Inheritance in Man database, are associated with spermatogenic failure. Among these are Kallmann syndrome and Noonan syndrome. In monogenic disorders, spermatogenic failure results from hypogonadotrophic hypogonadism, cryptorchidism, delayed puberty or male pseudohermaphroditism and ambiguous genitalia (Hardelin \& Dode 2008). In cystic fibrosis (CF), spermatogenesis is unaffected, but congenital bilateral aplasia of the vas deferens (CBAVD) causes ejaculatory azoospermia. Besides being part of the disorder CF, CBAVD may also present without the other clinical symptoms common to $\mathrm{CF}$, depending on the type of mutation in the CF transmembrane receptor gene. Although monogenic disorders are rare, they should not be overlooked in the workup of the male partner of the subfertile couple (Meschede \& Horst 1997).

Apart from these established causes, there is a large body of literature either claiming or refuting the association of certain genetic variants with spermatogenic failure (Matzuk \& Lamb 2008). Although the evidence in some of these studies is stronger than in others, the vast majority are single studies and for most of them no subsequent studies by other groups have confirmed the initial findings. Moreover, methodological and biological issues often confound these studies as outlined below.

\section{Methodological issues in the study of the genetics of spermatogenic failure}

First, many previous studies have included men based on their (reported) fertility, instead of their semen quality. Case-control association studies frequently included 'subfertile' men as cases and/or 'fertile', 'proven fathers' as controls without knowledge of their semen parameters. Since normozoospermic subfertile cases and oligozoospermic fertile controls are likely to have been included in these studies, no conclusions can be drawn with regard to the association between the genetic variant studied and spermatogenesis. It cannot be stated too often that subfertile is not the same as oligozoospermic, just as fertile is not synonymous with normozoospermic.

Second, due to the substantial interindividual variablilty of sperm counts, men may erroneously have been classified as normo- or oligozoospermic when only a single semen sample was used for classification (Tielemans et al. 1997, Alvarez et al. 2003).

Third, the case-control design in itself may not be the most suited design to study the effect of a putative genetic risk factor on spermatogenesis. Spermatogenesis is a quantitative, continuously distributed trait that shows large intra- and interindividual variation (Table 1). Therefore, a design that dichotomizes sperm counts is unable to detect a leftward shift of the sperm distribution curve, i.e. an overall reduction in sperm count, due to a genetic risk factor (Fig. 1).

Fourth, in many previous case-control studies, cases and controls were unmatched. Drawing cases and controls from different populations, for example using cases drawn from a clinical subfertile population and population samples as controls, may introduce selection bias. Another potential source of selection bias is the different ethnic background of included subjects. How to deal with these 'racial' differences is frequently debated in clinical, epidemiological and molecular research (loannidis et al. 2004). Some researchers argue that classification of patients according to ethnicity should be abandoned, because there would not be a correlation between common complex diseases and race, and genetic variation would be continuous and discordant with race (Cooper et al. 2003). However, there are known racial and ethnic differences in the cause, expression and prevalence of various diseases. Even with similar allele frequencies, i.e. similar genetic variation, the effect of a genetic risk factor may differ between ethnic groups (Burchard et al. 2003). In studies on spermatogenesis, geographic and ethnic differences in sperm quality have been reported between men in the Nordic-Baltic area (Jorgensen et al. 2002, Tsarev et al. 2005). In addition, a possibly differential effect of POLG genotype on spermatogenesis was described in men from Dutch Caucasian or African descent (Westerveld et al. 2008a).

Table 1 Semen parameters in a cohort of 1014 consecutively included men, part of a subfertile couple, compared to WHO citeria.

\begin{tabular}{lcl}
\hline Semen parameter & WHO cut-off & \multicolumn{1}{c}{ Cohort $^{\mathrm{a}}$} \\
\hline Volume $(\mathrm{ml})$ & 2 & $3.3 \pm 1.5$ \\
Concentration $\left(10^{6} / \mathrm{ml}\right)$ & 20 & $52(16-89)$ \\
Motility $(\%$ progressive $)$ & 25 & $32 \pm 16$ \\
Morphology $(\% \text { normal })^{\mathrm{b}}$ & 30 & $37(25-46)$ \\
Total count $\left(10^{6}\right)$ & 40 & $149(44-281)$ \\
Total motile count $\left(10^{6}\right)$ & 10 & $49(7-110)$ \\
\hline
\end{tabular}

${ }^{\mathrm{a} D}$ Data are presented as mean \pm s.D. or median (25th-75th percentile). ${ }^{b}$ According to WHO (1992). 


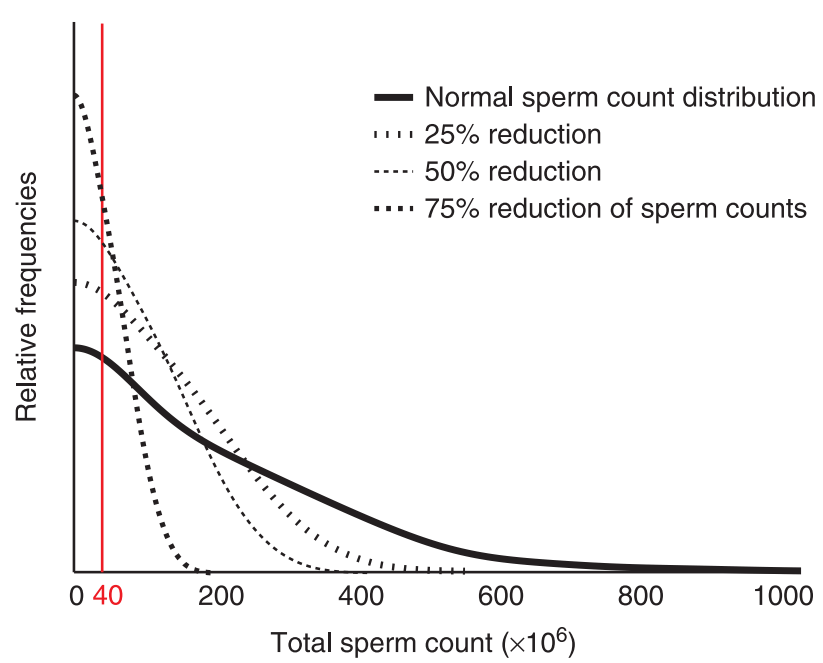

Figure 1 Distribution of total sperm counts in an unselected cohort of men (straight line). The sperm count distribution curve is shifted to the left, i.e. towards spermatogenic failure, in men carrying risk factors for spermatogenic failure (dashed lines). The red line indicates the $\mathrm{WHO}$ cut off value for normozoospermia.

\section{Biological issues in the study of the genetics of spermatogenic failure}

Besides the methodological issues described above, there are also some biological principles that should be taken into account when studying the genetics of spermatogenic failure.

The first issue concerns the biological consequences of the spermatogenic failure phenotype, notably the limited reproductive success of this phenotype. If a genetic locus is strongly linked to spermatogenic failure, the chances are that this locus will not, or scarcely, be spread to the next generation. This greatly hampers the application of linkage analysis, which is preferably carried out on large extended pedigrees. Although familial clustering of subfertility has been reported and segregation analysis has pointed to a heritable background, linkage analysis is unlikely to provide novel genetic loci, simply because spermatogenic failure and large pedigrees are likely to be mutually exclusive (Lilford et al. 1994, Gianotten et al. 2004).

Another biological issue relates to the characteristics of human spermatogenesis as compared with other mammals, notably rodents. Even though spermatogenesis in mice and men involves similar, highly evolutionary conserved processes, there are also many different processes involved that are likely to be governed by different sets of genes. This may limit the usefulness of another method to search for genetic factors underlying spermatogenic failure, namely the mutation screening of candidate genes derived from mouse knockout models. To date, there are over 400 mouse models with a reproductive phenotype (Matzuk \& Lamb 2008). Other studies providing candidate genes are those analysing expression profiles of rodent gametes throughout gametogenesis (Schultz et al. 2003, Schlecht et al. 2004, Chalmel et al. 2007). Although the generation of a multitude of mouse knockout models is of great value in fundamental research on mammalian fertility and spermatogenesis, the equivalents of artificially induced homozygous knockouts in mouse are indeed not commonly found in humans. In humans, it is usually heterozygous single base pair mutations or small deletions that are detected (Westerveld et al. 2005, 2006). Interestingly, in mouse knockout studies, the heterozygous deletion most often does not have a phenotype (O'Bryan \& de Kretser 2006). The natural occurrence of heterozygous gene mutations rather than the artificially induced homozygous gene deletions in humans reflects the fact that thousands of genes are involved in spermatogenesis and hence each single mutant is likely to occur spontaneously at extremely low frequency. Another difference between mice and men is that, in contrast to inbred mouse models, non-inbred human populations harbour large variation in environmental and genetic factors that may modulate the effects of genetic variants.

Finally, an enduring complicating factor of studies in the field is the lack of functional assays to assess the biological effect of genetic variants found in men with spermatogenic failure. Such assays are unavailable, either because the function of the encoded protein is unknown, or because there is no suitable cell system to test its function. To date, no human spermatogonial stem cell (SSC) line is available to let alone an in vitro system for SSC differentiation. Although such systems are becoming available in rat and mouse, these might not be ideal to study human spermatogenesis as mentioned earlier (van Pelt et al. 2002, KanatsuShinohara et al. 2003).

\section{Investigating the genetic basis for low semen quality: the way forward}

Evidently, all issues discussed above, both methodological as well as biological, should be taken into account when studying the genetic causes of spermatogenic failure. Below we will indicate how to deal with some of these issues.

When using a case-control design, it is a prerequisite that both cases and controls are defined and selected on the basis of their respective semen parameters to avoid bias/confounding that goes with the use of subfertile cases and fertile controls.

As it both avoids the introduction of a possible selection bias and does not require dichotomization of quantitative data, a cohort design is the most powerful to study genetic risk factors. By assembling a large cohort of men with varying sperm counts and comparing the sperm counts of men with and without a genetic variant, the effect of a genetic variant on the distribution of sperm 
counts can be observed. Using this design, we were able to clearly refute an association between the CAG repeat in the androgen receptor and the CAG repeat in the polymerase $\gamma$-gene and spermatogenic failure (Westerveld et al. 2008a, 2008b).

Another way to improve the chances of identifying genes associated with spermatogenic failure is by selecting groups of men with a very homogeneous phenotype, for example isolated asthenozoospermia, isolated teratozoospermia, meiotic arrest or Sertoli cellonly syndrome. It may well be that the phenotypes that are usually studied (azoospermia and oligozoospermia) are too heterogeneous, and actually include men with different underlying (testicular) phenotypes. The advantage of this approach is illustrated by the fact that causal mutations in the SYCP3 and SPATA 16 genes were found in groups of men with a very homogeneous phenotype, although for SYCP3 subsequent studies failed to find mutations in this gene (Miyamoto et al. 2003, Stouffs et al. 2005, Dam et al. 2007, Martinez et al. 2007).

Apart from the different methodological problems in previous studies, one technical issue applies to all of them. Nearly, all studies studied the effect of a single gene on spermatogenesis. As stated earlier, with thousands of genes involved in spermatogenesis and thus theoretically just as many in spermatogenic failure, chances of identifying individuals carrying one particular causal variant are extremely low. With the advent of high throughput screening methods, thousands of genes can now be studied at the same time. This should open up new opportunities in studying the genetic causes of spermatogenic failure (Aston \& Carrell 2009). Besides investigating base pair mutations, attention should also be given to the so-called copy number variants (CNV), DNA segments of $1 \mathrm{~kb}$ or larger which are present at variable copy numbers in comparison with a reference genome, including deletions, duplications and insertions (lafrate et al. 2004, Sebat et al. 2004, Feuk et al. 2006). CNVs make up a very large source of structural variation in the human genome and are thought to even outweigh the variation that is contained by single nucleotide polymorphisms (SNPs; Redon et al. 2006). Also, wholegenome expression arrays can be used to identify differentially transcribed genes in patients and controls. However, expression array data have to be interpreted with caution since differential expression can simply mirror the presence or absence of specific cell types in the testis rather than provide clues on which genes are involved.

\section{The future of genetic studies in spermatogenic failure}

Considering the few genetic factors that have so far been found to cause spermatogenic failure and the exhaustive lists of candidate genes, much work remains to be done. As outlined above, new insights should become available by 1) assembling large cohorts of men with
2) homogenous spermatogenesis-based phenotypes for 3) whole-genome analysis, at the level of SNPs, CNVs and eventually whole-genome sequencing. In addition, much progress can be made by establishing a human SSC culture and in vitro differentiation system to study the effects of genetic variants on human spermatogenesis. Hopefully, the findings from these types of studies will eventually lead to treatments for male subfertility.

\section{Declaration of interest}

There is no conflict of interest that could be perceived as prejudicing the impartiality of the work/research reported.

\section{Funding}

This work did not receive any specific grant from any funding agency in the public, commercial or not-for-profit sector.

\section{Acknowledgements}

We thank Prof. Fulco van der Veen for his comments on the manuscript.

\section{References}

Aitken RJ 2006 Sperm function tests and fertility. International Journal of Andrology 29 69-75 (discussion 105-108).

Alvarez C, Castilla JA, Martinez L, Ramirez JP, Vergara F \& Gaforio JJ 2003 Biological variation of seminal parameters in healthy subjects. Human Reproduction 18 2082-2088.

Aston KI \& Carrell DT 2009 Genome-wide study of single nucleotide polymorphisms associated with azoospermia and severe oligozoospermia. Journal of Andrology 30 711-725.

Bonde JP, Ernst E, Jensen TK, Hjollund NH, Kolstad H, Henriksen TB, Scheike T, Giwercman A, Olsen J \& Skakkebaek NE 1998 Relation between semen quality and fertility: a population-based study of 430 first-pregnancy planners. Lancet 352 1172-1177.

Bonduelle M, Wennerholm UB, Loft A, Tarlatzis BC, Peters C, Henriet S, Mau C, Victorin-Cederquist A, Van Steirteghem A, Balaska A et al. 2005 A multi-centre cohort study of the physical health of 5-year-old children conceived after intracytoplasmic sperm injection, in vitro fertilization and natural conception. Human Reproduction 20 413-419.

Burchard EG, Ziv E, Coyle N, Gomez SL, Tang H, Karter AJ, Mountain JL, Perez-Stable EJ, Sheppard D \& Risch N 2003 The importance of race and ethnic background in biomedical research and clinical practice. New England Journal of Medicine 348 1170-1175.

Chalmel F, Rolland AD, Niederhauser-Wiederkehr C, Chung SS, Demougin P, Gattiker A, Moore J, Patard J, Wolgemuth DJ, Jegou B et al. 2007 The conserved transcriptome in human and rodent male gametogenesis. PNAS 104 8346-8351.

Cooper RS, Kaufman JS \& Ward R 2003 Race and genomics. New England Journal of Medicine 348 1166-1170.

Dam AH, Koscinski I, Kremer JA, Moutou C, Jaeger AS, Oudakker AR, Tournaye H, Charlet N, Lagier-Tourenne C, van Bokhoven H et al. 2007 Homozygous mutation in SPATA16 is associated with male infertility in human globozoospermia. American Journal of Human Genetics 81 813-820.

Dohle GR, Halley DJ, Van Hemel JO, van den Ouwel AM, Pieters MH, Weber RF \& Govaerts LC 2002 Genetic risk factors in infertile men with severe oligozoospermia and azoospermia. Human Reproduction 17 13-16.

Ellis PJ, Furlong RA, Conner SJ, Kirkman-Brown J, Afnan M, Barratt C, Griffin DK \& Affara NA 2007 Coordinated transcriptional regulation patterns associated with infertility phenotypes in men. Journal of Medical Genetics 44 498-508. 
Feuk L, Carson AR \& Scherer SW 2006 Structural variation in the human genome. Nature Reviews. Genetics 7 85-97.

Gianotten J, Lombardi MP, Zwinderman AH, Lilford RJ \& van der Veen F 2004 Idiopathic impaired spermatogenesis: genetic epidemiology is unlikely to provide a short-cut to better understanding. Human Reproduction Update 10 533-539.

Guzick DS, Overstreet JW, Factor-Litvak P, Brazil CK, Nakajima ST, Coutifaris C, Carson SA, Cisneros P, Steinkampf MP, Hill JA et al. 2001 Sperm morphology, motility, and concentration in fertile and infertile men. New England Journal of Medicine 345 1388-1393.

Hardelin JP \& Dode C 2008 The complex genetics of Kallmann syndrome: KAL1, FGFR1, FGF8, PROKR2, PROK2, et al. Sexual Development 2 181-193.

lafrate AJ, Feuk L, Rivera MN, Listewnik ML, Donahoe PK, Qi Y, Scherer SW \& Lee C 2004 Detection of large-scale variation in the human genome. Nature Genetics 36 949-951.

Ioannidis JP, Ntzani EE \& Trikalinos TA 2004 'Racial' differences in genetic effects for complex diseases. Nature Genetics 36 1312-1318.

Jorgensen N, Carlsen E, Nermoen I, Punab M, Suominen J, Andersen AG, Andersson AM, Haugen TB, Horte A, Jensen TK et al. 2002 East-West gradient in semen quality in the Nordic-Baltic area: a study of men from the general population in Denmark, Norway, Estonia and Finland. Human Reproduction 17 2199-2208.

Kanatsu-Shinohara M, Ogonuki N, Inoue K, Miki H, Ogura A, Toyokuni S \& Shinohara T 2003 Long-term proliferation in culture and germline transmission of mouse male germline stem cells. Biology of Reproduction 69 612-616.

de Kretser DM 1997 Male infertility. Lancet 349 787-790.

De Kretser DM \& Baker HW 1999 Infertility in men: recent advances and continuing controversies. Journal of Clinical Endocrinology and Metabolism 84 3443-3450.

Lilford R, Jones AM, Bishop DT, Thornton J \& Mueller R 1994 Case-control study of whether subfertility in men is familial. BMJ 309 570-573.

Martinez J, Bonache S, Carvajal A, Bassas L \& Larriba S 2007 Mutations of SYCP3 are rare in infertile Spanish men with meiotic arrest. Fertility and Sterility 88 988-989.

Matzuk MM \& Lamb DJ 2008 The biology of infertility: research advances and clinical challenges. Nature Medicine 14 1197-1213.

Meschede D \& Horst J 1997 The molecular genetics of male infertility. Molecular Human Reproduction 3 419-430.

Miyamoto T, Hasuike S, Yogev L, Maduro MR, Ishikawa M, Westphal H \& Lamb DJ 2003 Azoospermia in patients heterozygous for a mutation in SYCP3. Lancet 362 1714-1719.

Noordam MJ \& Repping S 2006 The human Y chromosome: a masculine chromosome. Current Opinion in Genetics \& Development 16 225-232.

Nuti F \& Krausz C 2008 Gene polymorphisms/mutations relevant to abnormal spermatogenesis. Reproductive Biomedicine Online $\mathbf{1 6}$ 504-513.

O'Bryan MK \& de Kretser D 2006 Mouse models for genes involved in impaired spermatogenesis. International Journal of Andrology 29 76-89 (discussion 105-108).

Palermo G, Joris H, Devroey P \& Van Steirteghem AC 1992 Pregnancies after intracytoplasmic injection of single spermatozoon into an oocyte. Lancet 340 17-18.

van Pelt AM, Roepers-Gajadien HL, Gademan IS, Creemers LB, de Rooij DG \& van Dissel-Emiliani FM 2002 Establishment of cell lines with rat spermatogonial stem cell characteristics. Endocrinology 143 1845-1850.

Redon R, Ishikawa S, Fitch KR, Feuk L, Perry GH, Andrews TD, Fiegler H, Shapero MH, Carson AR, Chen W et al. 2006 Global variation in copy number in the human genome. Nature 444 444-454.

Reijo R, Lee TY, Salo P, Alagappan R, Brown LG, Rosenberg M, Rozen S, Jaffe T, Straus D, Hovatta O et al. 1995 Diverse spermatogenic defects in humans caused by $\mathrm{Y}$ chromosome deletions encompassing a novel RNA-binding protein gene. Nature Genetics 10 383-393.

Repping S, Skaletsky H, Lange J, Silber S, Van Der Veen F, Oates RD, Page DC \& Rozen S 2002 Recombination between palindromes P5 and $\mathrm{P} 1$ on the human $\mathrm{Y}$ chromosome causes massive deletions and spermatogenic failure. American Journal of Human Genetics 71 906-922.
Repping S, Skaletsky H, Brown L, van Daalen SK, Korver CM, Pyntikova T, Kuroda-Kawaguchi T, de Vries JW, Oates RD, Silber S et al. 2003 Polymorphism for a 1.6-Mb deletion of the human $\mathrm{Y}$ chromosome persists through balance between recurrent mutation and haploid selection. Nature Genetics 35 247-251.

Schlecht U, Demougin P, Koch R, Hermida L, Wiederkehr C, Descombes P, Pineau C, Jegou B \& Primig M 2004 Expression profiling of mammalian male meiosis and gametogenesis identifies novel candidate genes for roles in the regulation of fertility. Molecular Biology of the Cell $\mathbf{1 5}$ 1031-1043.

Schultz N, Hamra FK \& Garbers DL 2003 A multitude of genes expressed solely in meiotic or postmeiotic spermatogenic cells offers a myriad of contraceptive targets. PNAS 100 12201-12206.

Sebat J, Lakshmi B, Troge J, Alexander J, Young J, Lundin P, Maner S, Massa H, Walker M, Chi M et al. 2004 Large-scale copy number polymorphism in the human genome. Science 305 525-528.

Sha J, Zhou Z, Li J, Yin L, Yang H, Hu G, Luo M, Chan HC \& Zhou K 2002 Identification of testis development and spermatogenesis-related genes in human and mouse testes using cDNA arrays. Molecular Human Reproduction 8 511-517.

Silber SJ \& Repping S 2002 Transmission of male infertility to future generations: lessons from the $\mathrm{Y}$ chromosome. Human Reproduction Update 8 217-229.

Stouffs K, Lissens W, Tournaye H, Van Steirteghem A \& Liebaers I 2005 SYCP3 mutations are uncommon in patients with azoospermia. Fertility and Sterility 84 1019-1020.

Tielemans E, Heederik D, Burdorf A, Loomis D \& Habbema DF 1997 Intraindividual variability and redundancy of semen parameters. Epidemiology 8 99-103.

Tsarev I, Gagonin V, Giwercman A \& Erenpreiss J 2005 Sperm concentration in Latvian military conscripts as compared with other countries in the Nordic-Baltic area. International Journal of Andrology 28 208-214.

Tuerlings JH, de France HF, Hamers A, Hordijk R, Van Hemel JO, Hansson K, Hoovers JM, Madan K, Van der Blij-Philipsen M, GerssenSchoorl KB et al. 1998 Chromosome studies in 1792 males prior to intracytoplasmic sperm injection: the Dutch experience. European Journal of Human Genetics 6 194-200.

Visser L, Westerveld GH, Korver CM, van Daalen SK, Hovingh SE, Rozen S, van der Veen F \& Repping S 2009 Y chromosome gr/gr deletions are a risk factor for low semen quality. Human Reproduction 24 2667-2673.

Vogt PH, Edelmann A, Kirsch S, Henegariu O, Hirschmann P, Kiesewetter F, Kohn FM, Schill WB, Farah S, Ramos C et al. 1996 Human $Y$ chromosome azoospermia factors (AZF) mapped to different subregions in Yq11. Human Molecular Genetics 5 933-943.

Westerveld GH, Repping S, Lombardi MP \& van der Veen F 2005 Mutations in the chromosome pairing gene FKBP6 are not a common cause of nonobstructive azoospermia. Molecular Human Reproduction 11 673-675.

Westerveld GH, Korver CM, van Pelt AM, Leschot NJ, van der Veen F, Repping S \& Lombardi MP 2006 Mutations in the testis-specific NALP14 gene in men suffering from spermatogenic failure. Human Reproduction 21 3178-3184.

Westerveld GH, Kaaij-Visser L, Tanck M, van der Veen F \& Repping S 2008a CAG repeat length variation in the polymerase gamma (POLG) gene: effect on semen quality. Molecular Human Reproduction 14 245-249.

Westerveld H, Visser L, Tanck M, van der Veen F \& Repping S 2008b CAG repeat length variation in the androgen receptor gene is not associated with spermatogenic failure. Fertility and Sterility 89 253-259.

Zamudio NM, Chong S \& O'Bryan MK 2008 Epigenetic regulation in male germ cells. Reproduction 136 131-146.

Received 4 June 2009

First decision 13 July 2009

Revised manuscript received 25 August 2009

Accepted 22 September 2009 